\title{
Emotions as an Object of Information Exchange in Digital Culture
}

\author{
L. V. Astakhova* \\ South Ural State University, Chelyabinsk, Russia \\ *e-mail:astakhovalv@susu.ru \\ Received March 18, 2021
}

\begin{abstract}
In this article, we substantiate the factors for developing a discussion of the problem of emotions as an object of information exchange within the framework of the documentary sciences and propose directions for using the potential of the emotional function of social information in the process of interaction between a specialist in the field of scientific information and a user in a digital culture.
\end{abstract}

Keywords: social information, meaning, emotions, text, semantic analysis, assessment, information exchange, digital culture

DOI: $10.3103 / \mathrm{S} 0147688221030023$

\section{INTRODUCTION}

Social information is a meaningful communication message; it can be a carrier of knowledge, emotions, and motives, which are based on certain meanings [1, p. 124]. Therefore, any message performs cognitive, emotional, and/or control functions and contains the corresponding functional components [1, p. 134]. The task of the emotional component is to share feelings and experiences and to influence the emotional sphere of the recipient. The activity of any subject of production, storage, and distribution of spiritual values (which include information centers and libraries of any type) is associated with an emotional component. Emotions are an attribute of the content of not only transmitted information, but also the personality of its sender subject and recipient subject. The emotional burden of the social mission of these subjects is expressed in the evaluative function.

Despite the three part functional essence of social information, the information and documentary sciences have not paid due attention to its emotional component for some time. This is due to a number of problems, whose solution is problematic due to objective reasons: (1) the dominance of methodological approaches to information activities in information and documentary sciences, within which emotional information went beyond the attention of scientists; (2) the ideological orientation of the evaluation function of information activities; (3) lack of opportunities to formalize emotional information and information technology tools for its transmission; and (4) inattention of professional education to the development of the emotional intelligence of future specialists in the field of scientific and technical information. However, today, when the information sphere of society is radi- cally changing its forms and content, one should look at the problem of emotions as an object of information exchange from new methodological, organizational, technological, and pedagogical viewpoints.

\section{DEVELOPMENT FACTORS OF DISCUSSION OF THE PROBLEM OF EMOTIONS AS AN OBJECT OF INFORMATION EXCHANGE}

During the period of the rapid development of information technology and the cultural transformation of society, the objective conditions for solving the above problems changed, which has led to the emergence of factors that require the information and documentary sciences to revise the discussion of emotional information as an object of information exchange. Let us consider these factors.

FROM THE MONOPOLY OF THE DOCUMENTARY AND COMMUNICATION APPROACH IN INFORMATION SCIENCES TO THE SYNTHESIS OF APPROACHES THAT PROVIDE A SYSTEMATIC REPRESENTATION OF EMOTIONAL INFORMATION AS AN OBJECT OF OPERATION IN INFORMATION ACTIVITIES

For some time, the information and documentary sciences were dominated by the communication approach to information activities, within which attention was focused on the intermediary role of a specialist in the field of scientific and technical information in the communication system (documentconsumer), while the meanings of transmitted information (knowledge, emotions, and control impacts) were in the background. 
Increasing significance is now attached to other approaches based on the generation of meanings and analytical-synthetic processing of information and on the creative functions of information screen and book cultures, which are impossible without taking the value-emotional component of transmitted information, its sender, and recipient into account. This is due to the transitivity of modern society and the transformation of an information society into a knowledge society. The stage of successful informatization of information transmission means was gradually replaced by the stage of digitalization of the meanings of transmitted information. The rapid growth in the volume of social information has caused difficulties in accessing the information that is necessary and useful for each user, which exacerbated the problem of its semantic content.

The Decree of the President of the Russian Federation On National Goals and Strategic Tasks of the Development of the Russian Federation for the Period up to 2024 states that the main task is the humanitarian development of the country as the basis of economic prosperity, state sovereignty, and civilizational identity. At the same time, the main condition for achieving national goals and strategic objectives is the formation of a model of a moral, responsible, independently thinking, and creative personality. Institutes of scientific and technical information have traditionally been the subjects of the implementation of such tasks. Considering these problems within the framework of substantiating the concept of book and screen cultures from the viewpoint of the symbolic concept of culture, scientists define them as the creative and communication activities of human society. Their purpose is both creative activities and semantic social communication, that is, the movement of spiritual values, including meaningful messages, in time and space. Religion, literature, art, and science are cultural and communication activities, because they aim at creativity and social communication. The difference between book and screen cultures consists only in the means of carrying out activities: in book culture these are symbols in book form, and in screen culture these are audiovisual messages in the information technology system [2]. Therefore, it is quite natural that today the institutions of scientific and technical information must switch their attention to the meanings of transmitted social information and use both traditional and digital means of information exchange.

We have previously considered the imperatives of strengthening the interrelationships of the meanings of knowledge and emotions contained in transmitted information within the framework of the hermeneutic approach to information activities [3], in the process of its analysis in a cognitive context [4], etc. Much attention in these studies is paid to substantiating the high status of a specialist in the field of scientific and technical information in the process of identifying, understanding, interpreting, and disseminating mean- ings, that is, the knowledge and emotions contained in texts, in the information space. The emphasis was placed on the dialogue nature of the activity of such a specialist, his emotional-value cooperation with the consumer of information as an obligatory element of the fulfillment of the social mission.

Without setting ourselves the task of analyzing all methodological approaches to the study of emotions in professional activities in the information and documentary sciences, we note that social and philosophical studies of this problem are also of great interest. Within their framework, the approval of a new valuenormative consensus in society, the need for significant changes in the life of the individual and, as a consequence, the renewal of the methodological arsenal for solving the problem are substantiated. For this purpose, philosophers prove the heuristic nature of the information approach to world outlook security, defining it as such a view of the world that contributes to the survival of each individual person and humanity as a whole. The information approach presents society as a communication network, where any interaction is mediated by the processes of information exchange between social subjects. In this case, "the factors of worldview security are not so much a specific message as more general factors of an information kind: the principles of generation, processing, and interiorization of information" [5]. The meaning of information is substantiated here as a key point: "endowing a sign with a certain variable meaning that can lead to the creation of a semantic invariant (final interpretant) in the communication process, which is motivated by extra-linguistic reality and the variety of operational qualities of an object" [6]. Therefore, the authors of this approach are convinced that teaching the basic principles of working with information and conceptualizing consciousness will contribute to the worldview security of the individual, preventing manipulation of a person's consciousness.

Considering that the norm of modern science is methodological syncretism and intertheoreticism, excluding conceptual monopoly, this and many other methodological approaches (information, information-psychological, semiotic, synergetic, axiological, etc.) can make a significant contribution to the systemic understanding of the emotional component of transmitted semantic messages, emotional characteristics of their senders and recipients, the development of personality in the process of information exchange under new conditions.

\section{FROM OUTDATED FORMS OF IMPLEMENTATION OF THE EVALUATIVE FUNCTION OF INFORMATION ACTIVITIES TO SOCIAL MEDIA}

At all times, creativity has played an important role in the development of culture. The basis of any of its types: scientific, technical, and artistic types, is infor- 
mation; therefore, the development of a creative personality is the mission of all information and document organizations: libraries and information centers, which is consistent with guidance documents such as the Strategy for the Development of the Information Society in the Russian Federation for 2017-2030 (Approved by the Decree of the President of the Russian Federation as of May 9, 2017, No. 203), Regulations on the Federal State Information System National Electronic Library (Approved by the Decree of the Government of the Russian Federation as of February 20, 2019, No. 169), etc.

The current state of the State System of Scientific and Technical Information (SSSTI) requires the modernization of information support for the scientific and industrial sphere, taking the factors that ensure the formation and development of the National Information System into account. Thus, the directions for the development and implementation of a new scientific and information policy for the development of the AllRussian Institute for Scientific and Technical Information of the Russian Academy of Sciences have been defined [7]. The tasks of improving the information technology system for processing documents, issuing abstract journals, and developing databases of national and industry information analytical centers, as well as centers of scientific and technical information, require the development of methods and models for thematic, semantic, and linguistic analysis of texts, machine learning, artificial intelligence, and automating the recognition of the meanings of texts and images. According to experts, the quality of defining topics and classifying texts increases when combining the advantages of not only "machine learning methods, automatic document classification, thematic indexing and algorithms for extracting semantics from text, support vector methods, decision trees, concept and terminology extraction, keywords, and self-referencing," but also "selection of semantic and evaluative information from the text" [8].

The external technological and social environment, changes in the field of scientific communications, education, and modernization of data management systems have had a significant impact on the professional activities of the subjects of the information and documentary sciences industry. Today, we are witnessing the loss of direct contact with information users who have moved to the information Internet space and, as a result, difficulties in implementing the traditional social function of library and information organizations. Humanitarian pedagogical technologies that were familiar to traditional book culture are alien to digital culture. Since the function of personality development has come to the fore under modern conditions, there is a need for a more rapid pace of development of new digital forms and content of work with Internet users. Thus, scientific (academic) and public libraries strive to serve readers using modern information technologies, create spatial environments for creativity and intellectual leisure, provide comfortable service conditions, and improve the skills and abilities of librarians in accordance with the changing preferences of users. This creates the preconditions for an optimistic vision of the future of libraries not only as repositories of information, but also as centers of intellectual leisure, communication platforms, places for learning, coworking, creativity, and inspiration [9]. Studies on modern trends in the development of foreign and Russian library web environment have revealed that the leading libraries use them at a $67 \%$ level, while other libraries use them only at a $33 \%$ level [10]. The most common social media of various types are as follows [11]: global and national social networks (Facebook, LinkedIn, Odnoklassniki, VKontakte, Qzone, Mixi, Copainsd'avant), creative exchange sites (YouTube, Instagram, Douban, Flickr), sharing sites (Wikipedia), instant messengers (Skype, WhatsApp, WeChat, Telegram), blogging and microblogging platforms (Twitter, LiveJournal, SinaWeibo, Ameba, and Plurk).

Social media have become popular work tools especially for foreign information industry organizations. Libraries are actively developing social marketing to link social media to the mission of the library and use them creatively to communicate effectively with users. Scientists are actively studying user needs, the contents of social networks, and interactions within networks [12]. As an example, the analysis in [13] showed that Instagram and Facebook, as well as Twitter, were most frequently used during the COVID-19 lockdown by Polish university libraries. Libraries used YouTube to a much lower extent. However, during the lockdown, not all university libraries were equally active on social media, despite the availability of content and ease of interaction. Another study found that the most popular social media platforms for librarians were Twitter, Facebook, and LinkedIn [14]. At the same time, it is important that the greatest interest of visitors to social networks is caused by messages related to communication and video messages [15].

The foreign press pays special attention not only to the diversification of forms, but also to the expansion of the content of information network interaction with users through knowledge and emotions. A study by American specialists showed that messages on the pages of the university library in social networks contained not only information about archives, collections, exhibits, university, and library communities and services, but also messages about events and the mood of the collective [16]. As an example, during the 2018 hurricane in Carolina, public libraries shared information about the disaster on Twitter, additionally serving as emergency information centers [17].

More evaluative information is required for orientation in the stream of destructive influences. Libraries are already considered an important player in the 
fight against the phenomenon of fake news, and there is evidence of the success of strategies and methods to combat these phenomena [18]. As an example, the University of Hong Kong concluded that social media should not be used as just a bulletin board, but instead it is necessary to adapt to an entertaining and interactive communication style and make the most of social media functions to communicate with users: organize interactive photo contests for students so that they could interact with the library [19]. To enrich social media content, one Canadian university works under the Instagram curator program, in which the opportunity to show one's own views and experiences is given to one university student per month [20], etc. Of course, user involvement expands the emotional space of any information organization. The rapid development of social marketing in foreign libraries [21] allows marketers to work successfully at libraries.

In Russia, much attention is paid to marketing technologies for promoting library sites. The most common tool is the publication of press and post releases, and the least used technology is embedded blogs, video, and Internet broadcasts, as well as website optimization for an audience from social networks [22]. It is also known [23] that the methods of communication between a library and its own readers require updating, the use of a variety of means for communication, exchange of information, the introduction of a wide range of opportunities for self-development and self-improvement of the user, and an appropriate experience appears.

It is gratifying that the discussion of the problems of information activity has given rise to an emotionally rich concept such as trust. Trust is considered a prerequisite for the development of social capital and plays a decisive role in building relationships between employees of any organization and its contacts with the external environment. Experts associate the functioning of social media with trust: "groups of people, members of network communities perceive information in terms of the values they share, trust the information product received from people who share their values, and members of their network communities," which "allows increasing the trust of information recipients" [24, p. 155]. As an example, the experience of building trust with local people visiting the library has been fruitful. Librarians have a high level of trust in other people, and respondents who declare trust in others also have a higher level of individual social capital and are more willing to engage in charity and civic activities; family and friends are important to them, etc. [25]. Such pro-social attitudes associated with trust are important for the development of emotional saturation of information exchange and the performance of social functions of any organization of an information and document orientation.
FROM THE COMPLEXITY OF FORMALIZING

THE EMOTIONS TO AUTOMATIC EMOTION RECOGNITION AND THE SENSORY EMOTIONAL NETWORK WEB 5.0

Until the early 21 st century, the complexity of formalizing emotions was the axiom in science and practice. In the 1990s, the following statement was indisputable: "So far there are no means of analyzing the content structure of emotional information, although there are numerous attempts to use the information approach in the field of art (theory of aesthetic information and semiotics of art)" [1, p. 136]. However, today, the prospects for the evolution of the World Wide Web are associated with the development of the sensory-emotional network (Web 5.0). In the future, we will deal with this particular network, and, more than ever before, there will be a high human need for the use and development of intra- and interpersonal emotional competences [26]. The Web 5.0 is a sensory-emotional, sensitive space in which we can transfer the Internet from an emotionally flat environment to a space of emotionally rich interactions [27]. Web 5.0 will be focused on the individual, it will be able to perceive his emotions and respond accordingly, as well as discover the subtleties that make stronger interactions possible [28].

At the moment, the Internet is emotionally neutral and does not perceive what users feel, but although emotions are still difficult to display, there are already technologies that can measure their impact. One example is www.wefeelfine.org, which tracks emotional phrases on the Internet, classifies them, and records the frequency and location of mood clusters. Another example is the Emotiv Systems Company, which has created neurotechnology. Using headphones, users can interact with content that reacts to their emotions and changes the facial expressions of their avatars in real time. If interaction can then be personalized to create an exciting experience for users, Web 5.0 will undoubtedly be more emotional than its predecessors. [26] At the end of 2020, Sberbank began to apply a new method of analyzing debtors' voices in call centers, which makes it possible to assess the intonation of customers during telephone conversations and read their emotions (joy, surprise, neutral, fear, despondency, irritation, or anger) to create a further dialogue scenario [29]. New technologies are also beginning to be applied in education. An automated software package has been developed for processing facial expression features for diagnosing emotional mental states of students during theoretical tests [30]. The emotional state of students is assessed by the index of their positive emotions.

This area is also developing in professional information activities. Experts propose to analyze the behavior of information consumers using artificial intelligence mechanics: A/B split testing in SEO, chat bots, personalization, instant messengers, stories on 
social networks, content marketing, social commerce, omnichannel marketing, augmented reality (AR) and immersive technologies, geomarketing, and user generated content. Thus, the authors of [31] placed emphasis on the information openness and transparency of an institution, providing access to exclusive information resources and familiarizing readers with the values of culture and art. In their opinion, it is especially advisable for libraries to use omnichannel marketing tools, which involves the use of several platforms (social networks, a website, a content blog, and applications) to popularize bibliographic products, methodological developments, blogs for professionals, and exhibition events. This will allow libraries to create additional value, increase brand credibility, and create a loyal audience and will permit librarians to be competitive specialists in the media space of the modern user.

\section{FROM INATTENTION TO THE EMOTIONAL INTELLIGENCE OF SPECIALISTS IN THE FIELD OF INFORMATION ACTIVITIES TO THE ACCELERATION OF ITS DEVELOPMENT WITHIN THE FRAMEWORK OF PROFESSIONAL EDUCATION}

In addition to digital skills, the current key requirement for a specialist in the field of information activities is the presence of emotional intelligence, including empathy as the ability to understand emotions, intentions, and motivation, as well as the ability to manage her own emotions and the emotions of other people [32].

The importance of soft skills in library and information activities is declared in the professional press [33]. These are also important for librarians working with researchers, fostering the development of relationships with users and creation of a variety of data services [34]. British scientists write about soft skills, indicating that they are necessary for specialists supporting scientific communication [35]. Soft skills of building relationships, cooperation, listening, hearing, and supporting are in demand today in the profession in the field of information activities in data management [36]. The skills of active reaction (paying attention, holding judgment, reflecting, explaining, summarizing, and sharing) and building trust from the viewpoint of creating a safe environment are very important for the information specialist [37]. The study [38] showed that individual aspects of personality (mutual respect, tolerance, trust, open and vivid communication, and listening skills) were the strongest factor that influences the cooperation of teachers and librarians at universities.

Russian experts also have made the conclusion that possession of nonspecialized supra-professional (soft) skills (communication skills, emotional intelligence, thinking with consideration for results and processes, etc.) along with a complex of professional knowledge, is the key to increasing the efficiency and relevance of libraries in an intensively developing environment [39]. There are already isolated practical examples of training future specialists in the information and documentary sciences in Internet marketing tools, which in the future will allow them to carry out the internal and external optimization of sites of informationlibrary and archival institutions such as compiling the semantic core of the site, the portrait of a potential user, the response from social networks to the site, etc., using GoogleTrends, Yandex Wordstat, and Yandex Metrica services [40]. However, the purposeful development of the emotional intelligence of such specialists is required. In the world educational practice, a certain experience has already been accumulated in this area within the framework of higher education, see, e.g., [41]. Training programs in specially created institutes and EC-training (EC is emotional competence) are implemented in the workplace [42]. Therefore, it is very important today to include emotional competencies in state educational standards for training specialists in the field of information and documentary sciences, as well as in programs for their retraining and advanced training.

Under the conditions of the upcoming sensoryemotional network Web 5.0, the development of the emotional competence of users as full-fledged subjects of information exchange is of great importance. Scientific and technical information organizations can meet this challenge as part of the development of the digital culture of their users.

\section{CONCLUSIONS}

The tripartite functional essence of social information requires that the information and documentary sciences must be focused on emotional components: transmitted information, the personality of an information sender, and the personality of its recipient.

For some time this was hindered by: (1) the dominance of methodological approaches to information activities in information sciences, within the framework of which emotional information went beyond the attention of scientists; (2) the ideological orientation of the implementation of the evaluation function of information activity in the form of guidance in reading and compiling recommendatory bibliographic lists; (3) the impossibility of formalizing emotional information and tools for its assessment and transmission; and (4) inattention of professional education to the development of the emotional intelligence of future specialists, including information ones.

During the period of modern cultural transformation of society, the objective conditions for solving the problems identified here have changed, which has led to the emergence of factors that require the information and documentary sciences to revise emotional information as an object of information exchange. The 
factors and driving force behind the development of such a discussion of the problem of emotions as an object of information exchange within the framework of the documentary sciences are as follows: the end of the methodological monopoly in the research of social information; deepening of the emotional and evaluative richness of information activities of information institutions in the creation of information resources and their dissemination using social media as tools of social marketing; the emergence of technical capabilities for recognizing emotions and the prospects for the development of the sensory-emotional network Web 5.0 ; and introduction of the use of innovative technologies for the development of emotional competence of future specialists in the field of information activities in professional education.

The movement of science and practice in the directions indicated in this article would provide the potential of the emotional components of social information in the process of interaction between a specialist in the field of scientific and technical information and a user under new conditions, to strengthen the position of institutions of the information sphere as subjects of the development of the digital culture in society.

\section{FUNDING}

This article was prepared under the support of the Government of the Russian Federation (Resolution No. 211 as of March 16, 2013), agreement no. 02.A03.21.0011.

\section{REFERENCES}

1. Sokolov, A.V., Vvedenie v teoriyu sotsial'noi kommunikatsii (Introduction to the Theory of Social Communication), St. Petersburg: SPbGUP, 1996.

2. Sokolov, A.V., Book culture and screen culture in social communication, in Leksikograficheskaya kopilka. Sb. nauch. statei (Lexicographic Bank. Scientific Papers), St. Petersburg, 2020, pp. 4-20.

3. Astakhova, L.V., Bibliografiya kak nauchnyi fenomen (Bibliography as a Scientific Phenomenon), Moscow: Mosk. Gos. Univ. Kul't., 1997.

4. Astakhova, L.V., Cognitive paradigm in modern bibliographic science, Nauchn. Tekh. Bibl., 2018, no. 6, pp. 3-22.

5. Fedotova, M.G., Information approach in the study of world outlook security: To the formulation of the problem, Sib. Filos. Zh., 2019, vol. 17, no. 1, pp. 66-75.

6. Fedotova, M.G., The concept of "denotation" in the semiotic theories of F. de Saussure and C.S. Pierce, $I z v$. Penzensk. Gos. Pedagog. Univ. im. V.G. Belinskogo, 2012, no. 27 , pp. 417-421.

7. Syuntyurenko, O.V. and Dmitrieva, E.Yu., The State System for Scientific and Technical Information within the Objectives of the Digital Economy, Sci. Tech. Inf. Process., 2019, vol. 46, pp. 288-297.

8. Sukhoruchkina, I.N. and Sukhoruchkina, A.A., Review of information technology factors in determining subjects of electronic and printed documents of Rus- sian and world scientific and technical literature, Yazyk. Kul'tura. Perevod: Nauchnye paradigmy i prakticheskie aspekty. Sb. nauch. trudov (Language. Culture. Translation: Scientific Paradigms and Practical Aspects. Scientific Papers), Moscow, 2020, pp. 292-297.

9. Red'kina, N.S., World trends in the development of libraries: Optimism vs pessimism (based on materials from foreign literature). Part 2, Bibliosfera, 2019, no. 1, pp. 49-58.

10. Ryabova, I.I. and Red'kina, N.S., Analysis of the efficiency of libraries in the web environment taking into account modern trends in the development of the web space, Sb. tezisov dokladov Mezhdunar. nauchno-prakt. konferentsii "Nauka, tekhnologii $i$ informatsiya $v$ bibliotekakh (Libway-2019)" (Abstracts of Reports of the International Scientific and Practical Conference "Science, Technology, and Information in Libraries (Libway-2019)), Novosibirsk, 2019, pp. 186-187.

11. Popov, E.V., Simonova, V.L., and Komarova, O.V., Effects of social media in the digital economy, Vestn. Ural. Fed. Univ., Ser. Ekon. Upr., 2019, vol. 18, no. 2, pp. $168-185$.

12. Hong Cheng, W.W., Lam. E.T.H., and Chiu, D.K.W., Social media as a platform in academic library marketing: A comparative study, J. Acad. Librarianship, 2020, vol. 46, no. 5, 102188. https://www.sciencedirect.com/science/article/pii/S0099133320300914. Cited March 17, 2021.

13. Gmiterek, G., Polish university libraries social networking services during the COVID-19 pandemic spring term lockdown, J. Acad. Librarianship, 2021, vol. 47, no. 3, 102331. https://www.sciencedirect.com/science/article/pii/S0099133321000227. Cited March 17, 2021.

14. Smith, D., Chapter 2 - Libraries and Social Media, in Growing your Library Career with Social Media, Chandos Publ., 2018, pp. 15-26. https://www.sciencedirect.com/science/article/pii/B9780081024119000029. Cited March 17, 2021.

15. Lam, E.T.H., Cheuk Au, C., and Chiu, D.K.W., Analyzing the use of Facebook among university libraries in Hong Kong, J. Acad. Librarianship, 2019, vol. 45, no. 3, pp. 175-183. https://www.sciencedirect.com/science/article/pii/S0099133318304300. Cited March 17, 2021.

16. Harrison, A., Burress, R., Velasquez, S., and Schreiner, L., Social media use in academic libraries: A phenomenological study, J. Acad. Librarianship, 2017, vol. 43, no. 3, pp. 248-256. https://www.sciencedirect.com/science/article/pii/S0099133317300198. Cited March 17, 2021.

17. Nann, A. and Verishagen, N., Chapter 2 - social media committees: Sharing the library's voice, in Social Media. The Academic Library Perspective, Verishagen, N., Ed., Chandos Publ., 2019, pp. 15-34. https://www.sciencedirect.com/science/article/pii/B978008102409600002-X. Cited March 17, 2021.

18. Revez, J. and Corujo, L., Librarians against fake news: A systematic literature review of library practices (Jan. 2018-Sept. 2020), J. Acad. Librarianship, 2021, vol. 47, no. 2, 102304. https://www.sciencedirect.com/science/article/pii/S0099133320301956. Cited March 17, 2021. 
19. Chan, T.T.W., Lam, A.H.C., and Chiu, D.K.W., From Facebook to Instagram: Exploring user engagement in an academic library, J. Acad. Librarianship, 2020, vol. 46, no. 6, 102229. https://www.sciencedirect.com/science/article/pii/S0099133320301208. Cited March 17, 2021.

20. Winn, D., Rivosecchi, M., Bjerke, J., and Groenendyk, M., MTL 2.0: A report on the social media usage and user engagement of the "Big Four" academic libraries in Montréal, J. Acad. Librarianship, 2017, vol. 43, no. 4, pp. 297-304. https://www.sciencedirect.com/science/article/pii/S009913331630180X. Cited March 17, 2021.

21. Canzoneri, B.R., 9 - Why a marketing background is a good fit for the library profession, in Skills to Make a Librarian, Lowe-Wincentsen, D., Ed., Chandos Publ., 2015, pp. 91-103. https://www.sciencedirect.com/science/article/pii/B9780081000632000090. Cited March 17, 2021.

22. Rykhtorova, A.E., World trends in marketing technologies for promoting library sites, Bibliotekovedenie, 2020, vol. 69 , no. 2 , pp. 135-146.

23. Kulikova, E.S., Methods of forming an organization's image using digital marketing on the example of a university reading room, Perspekt. Nauki, 2020, no. 7, pp. $163-165$.

24. Besler, M.G., Combining social and mass media resources to increase the trust of information recipients, Strategich. Kommun. Biz. Polit., 2018, no. 4, pp. 152157.

25. Wojciechowska, M., Trust as a factor in building cognitive social capital among library workers and users. Implications for library managers, J. Acad. Librarianship, 2021, vol. 47 , no. 1, 102300. https://www.sciencedirect.com/science/article/pii/S0099133320301919. Cited March 17, 2021.

26. Benito-Osorio, D., Peris-Ortiz, M., Armengot, C.R., and Colino, A., Web 5.0: The future of emotional competences in higher education, Global Bus. Perspect., 2013, vol. 1, pp. 274-287.

27. Kambil, A., What is your Web 5.0 strategy?, J. Bus. Strategy, 2008, no. 29, pp. 56-58. https://doi.org/10.1108/02756660810917255

28. Spisak, K., Eras of the web - Web 0.0 through Web 5.0, September 13, 2019. https://www.business2community.com/tech-gadgets/eras-of-the-web-web-0-0-throughweb-5-0-02239654. Cited March 17, 2021.

29. Sberbank's Collectors Introduced Technology for Recognizing the Emotions of Debtors. https://www.rbc.ru/finances/18/02/2021/602d2aac9a79472a463bc4ad. Cited March 17, 2021.

30. Bich, N.N. and Assanovich, B.A., An adaptive approach to assessing students' knowledge based on the index of their positive emotions, Tr. Belorus. Gos. Tekh. Univ., Ser. 3, 2019, no. 1, pp. 57-63.

31. Khvostova, T.M., Shtratnikova, A.V., and Urzhumova, O.M., Relationship marketing technology: Relevance for libraries, Innovatsii Investitsii, 2020, no. 11, pp. 164-166.

32. Russia 2025: From Personnel to Talents, The Boston Consulting Group, Inc., 2017. http://d-russia.ru/wpcontent/uploads/2017/11/Skills_Outline_web_tcm26175469.pdf. Cited July 20, 2019.

33. Matteson, M.L., Anderson, L., and Boyden, C., "Soft skills:" A phrase in search of meaning, Portal, 2016, vol. 16 , no. 1, pp. 71-88.

34. Federer, L., Defining data librarianship: A survey of competencies, skills, and training, J. Med. Libr. Assoc., 2018, vol. 106, no. 3, pp. 294-303.

35. Read, A. and Cox, A., Underrated or overstated? The need for technological competencies in scholarly communication librarianship, J. Acad. Librarianship, 2020, vol. 46, no. 4. 102155. https://www.sciencedirect.com/science/article/pii/S0099133320300586. Cited March 17, 2021.

36. Khenderson, M., Why soft and non-technical skills are necessary for success in the profession of data librarian, Mezhdunar. Forum Inf., 2020, vol. 45, no. 4, pp. 33-36.

37. Rinehart, A.K., Getting emotional about data: The soft side of data management services, Coll. Res. Libr. News, 2015, vol. 76 , no. 8, pp. 437-440.

38. Nguyen, T.L. and Tuamsuk, K., Factors influencing the faculty-librarian collaboration at the Vietnamese universities, J. Acad. Librarianship, 2020, vol. 46, no. 2. 102130. https://www.sciencedirect.com/science/article/pii/S0099133319304045. Cited March 17, 2021.

39. Red'kina, N.S., "Over-professional” skills and professional knowledge of a library specialist: The requirements of the time, Bibliotekovedenie, 2019, vol. 68, no. 6, pp. 647-658.

40. Malysheva, E.N. and Ulenko, Yu.V., Teaching students the tools of Internet marketing (on the example of the areas of training "Library and Information Activities," "Documentation and Archival Science"), Biz., Obraz., Pravo, 2019, no. 3, pp. 379-383.

41. Rybakova, N.A., Emotional competence of a teacher: an essential characteristic, Pedagog., Vopr. Teor. Prakt., 2019, vol. 4, no. 4, pp. 190-195.

42. Assessing social, emotional, and intercultural competences of students and school staff: A systematic literature review, Educ. Res. Rev., 2020, vol. 29, 100304. https://doi.org/10.1016/j.edurev.2019.100304

Translated by L. Solovyova 